Salto, Graciela. "Anclajes: itinerarios de una revista”. Anclajes, vol. XXV, n. ${ }^{\circ}$, septiembre-diciembre 202I, pp. I-3.

https://doi.org/10.19137/anclajes-2021-2531

\title{
ANCLAJES: ITINERARIOS DE UNA REVISTA
}

\section{Graciela Salto}

\author{
Universidad Nacional de La Pampa \\ Consejo Nacional de Investigaciones Científicas y Técnicas, CONICET \\ Argentina \\ gsalto@conicet.gov.ar \\ ORCID: 0000-000I-5305-772X
}

Fecha de recepción: 30/06/202I | Fecha de aceptación: |2/07/2021

\begin{abstract}
Resumen: Los veinticinco volúmenes de Anclajes convocan reflexiones sobre los avances producidos en la crítica y la edición universitaria en las últimas décadas. Un grupo notable de especialistas analiza los aportes de la publicación en temáticas como memorias y violencias, post-humanismos, escrituras del yo, cuerpos y subjetividades disidentes, revisiones del archivo y del canon, de lenguas y culturas imaginadas.
\end{abstract}

Palabras clave: revistas académicas; edición de revistas; crítica literaria; siglo XXI.

\section{Anclajes: journal itineraries}

Abstract: The twenty-five volumes of Anclajes call for a reflection on the development of cultural criticism and university publishing in recent decades. A notable group of specialists analyzes the contributions of the journal on topics such as memories and violence, post-humanisms, writings of the self, dissident bodies and subjectivities, revisions of the archive and the canon of imagined languages and cultures.

Keywords: academic journals; edition; literary criticism; XXI century.

\section{Anclajes: itinerários da revista}

Resumo: Os vinte e cinco volumes de Anclajes convocam reflexões sobre os avanços produzidos na crítica e na edição universitária nas últimas décadas. Um grupo notável de especialistas analisa as contribuições da publicação em temas como memórias e violência, pós-humanismos, escritos de si, corpos dissidentes e subjetividades, revisões do arquivo e do cânone, de línguas e culturas imaginadas.

Palavras chave: Revistas acadêmicas; edição; Crítica literária; Século XXI. 

de Anclajes. La revista se inició a fines del siglo pasado y, desde entonces, recorrió un itinerario acorde a las pulsiones y movimientos de la crítica y las demandas de las universidades públicas y del sistema científico en general. Los volúmenes impresos en los inicios con periodicidad anual se transformaron en la actual edición en línea con tres números anuales en acceso abierto y su contenido recuperado en más de veinte directorios, catálogos, sistemas de indización y bases de datos. El esfuerzo inicial de cinco personas, convocadas en 1997 bajo el legado de María Cristina Gil de Gates en el Instituto de Análisis Semiótico del Discurso, se multiplicó en el equipo interinstitucional de hoy.

El Instituto de Investigaciones Literarias y Discursivas (IILyD), nombre adoptado por la misma institución en 2012, edita Anclajes en el portal de revistas de la Universidad Nacional de La Pampa (CERAC) junto a especialistas de diversas universidades del país y del exterior. Se suma, además, el asesoramiento y monitoreo continuo de un referato externo en el cual participan, bajo la modalidad del doble anonimato, cerca de un millar de personas que aportan la mayor especificidad temática y diversidad institucional posible al proceso de evaluación. Es así como, en los últimos años, Anclajes se ubica en los primeros lugares entre las revistas de literatura o estudios literarios publicadas en la Argentina y en una posición de relevancia en el ámbito internacional ${ }^{1}$. De hecho, los artículos publicados configuran hoy un corpus en el que se analizan las tendencias de las investigaciones literarias de las últimas décadas y la inserción de publicaciones académicas como esta en un escenario editorial cada vez más complejo ${ }^{2}$.

$\mathrm{Su}$ lectura sostenida y amplia, con registros de autoría y de lectura situados en cuatro continentes, se sostiene en la visión y el trabajo del equipo editorial durante tantos años, en las políticas de la institución editora y en la más reciente opción por el acceso abierto ${ }^{3}$. Este último factor, en consonancia con un reclamo

1 Sin desconocer las limitaciones de los sistemas de métricas, pueden consultarse como orientación los resultados del Scimago Journal of Country Rank, SJR (https://www.scimagojr.com/journalrank.php), la Red Iberoamericana de Conocimiento Científico, REDIB (https://redib.org/Ranking/Revistas?lng=es), con sede en España, y la Red de Revistas de América Latina y del Caribe, Redalyc, con sede en México (https://www.redalyc.org/revista.oa?id=224\&tipo=indicadores), entre otras instancias de evaluación de las revistas universitarias.

2 Véanse, por ejemplo, los aportes de Romanos de Tiratel, S., Giunti, M. G. y Parada, A. "Las revistas argentinas de filología, literatura y lingüística: visibilidad en bases de datos internacionales". Ciência da Informação, vol. 32, n. ${ }^{\circ} 3$, 2003, pp. 128-139, https://doi.org/10.1590/ S0100-19652003000300015; Fernanda Beigel y Maximiliano Salatino, "Circuitos segmentados de consagración académica: las revistas de Ciencias Sociales y Humanas en la Argentina". Información, cultura y sociedad, n. ${ }^{\circ}$ 32, junio 2015, pp. 7-32; Lacalle, Juan Manuel y Vilar, Mariano Alejandro. "Estudios literarios y lectura distante: un primer acercamiento a la actualidad de la investigación en las revistas académicas argentinas". Anclajes, vol. XXIII, n. ${ }^{\circ}$ 1, 2019, pp. 1940, https://doi.org/ 10.19137/anclajes-2019-2312.

3 Según los indicadores más recientes de Redalyc, el 43.4\% de los artículos de Anclajes fueron descargados en Estados Unidos, el 24.5\% en Alemania, el 17,9\% en México, el 4\% en China, y el $8.6 \%$ en Argentina (https://www.redalyc.org/revista.oa?id=224\&tipo=indicadores). Sobre las políticas de acceso abierto, pueden consultarse la Resolución N. ${ }^{\circ} 329 / 2015$ del Consejo Superior 
general por la circulación más democrática y horizontal del conocimiento, potencia la difusión de una agenda crítica descentrada que, desde una universidad ubicada en la periferia de las instituciones metropolitanas, ha logrado acompañar y, en muchos casos, anticipar los cambios o rearticulaciones del campo disciplinar.

En este número se publica un dosier que traza algunas de estas líneas de cruce entre publicaciones de la revista y movimientos de la crítica que van desde los inicios de Anclajes hasta sus modulaciones más recientes. Especialistas del país y del exterior revisan lo publicado y compulsan su relación con los enfoques críticos predominantes en un espacio inestable, sujeto a continuos reajustes de perspectivas y actualización de lecturas. Los temas y acercamientos que se detectan son múltiples, aunque, en su diversidad, muestran una trama de intereses en la que predominan los estudios sobre la contemporaneidad, la crisis de la representación, el desmontaje de un pasado ominoso y las nuevas configuraciones de los cuerpos y las subjetividades. Roxana Patińo traza algunos de estos ejes generales mientras que Emilia Deffis y Rossana Nofal dedican sendos ensayos a analizar los aportes de Anclajes a los estudios sobre las memorias, las violencias y los testimonios de las postdictaduras en el Cono Sur. José Amícola proyecta el recorrido desde los primeros artículos en considerar el sistema sexo-género hasta los más recientes estudios queer y, en una línea convergente, Rafael M. Mérida Jiménez celebra la difusión en la revista de artículos sobre feminidades y masculinidades. Irina Garbatzky rescata un número no menor de artículos que amplían el canon al complejizar la relación de lo literario con otras zonas del archivo cultural. Verónica Delgado y Geraldine Rogers analizan las contribuciones de la revista a la historia de las publicaciones periódicas y la sociología de la edición. Andrea Bocco, Hernán Pas y Hernán Sosa dedican tres artículos de autoría individual al abordaje crítico de lo publicado sobre el siglo XIX y Juan Antonio Ennis, a su vez, analiza el espacio otorgado a los estudios sobre ideologías de las lenguas e historiografía lingüística. Marisa Malvestitti, María Emilia Orden y Alejandra Regúnaga rescatan, además, los aportes a las investigaciones sobre lenguas y culturas indígenas.

En conjunto, el dosier ofrece varios estados de la cuestión que exceden los límites de la revista y trazan un panorama de los cambios producidos en la crítica literaria y cultural de las últimas décadas. A quienes colaboran en este dosier, a quienes eligen la revista para publicar sus manuscritos, a quienes participan en el referato y a quienes la leen y consultan a diario, el equipo editorial agradece su compromiso con la producción, edición y circulación del conocimiento desde una universidad nacional donde este año se conmemoran los cincuenta ańos de vida institucional de la Facultad de Ciencias Humanas.

de la Universidad Nacional de La Pampa (UNLPam) sobre la creación del Consejo Editorial de Revistas Académicas y Científicas (CERAC) y la Resolución N. 230/2020 sobre Reglamento del Portal de Revistas de la UNLPam. Disponibles en: https://actosresolutivos.unlpam.edu.ar/. 